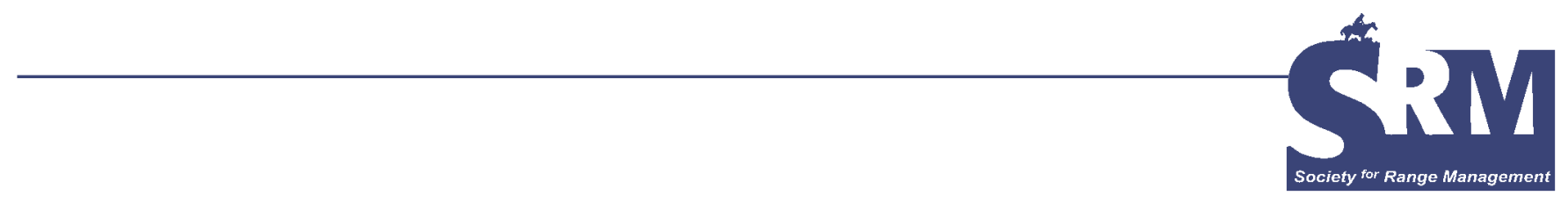

\title{
Keep an Eye on Your Keys
}

\section{By Matt Mattox}

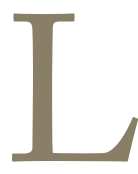

osing your keys can put a damper on the beginning of a beautiful day. If you've simply misplaced them but know they're around somewhere, the worst that usually happens is you have to put other things on hold and locate them. If the search reveals that you have truly lost your keys, the next step is to get some new keys made. Frustration, wasted time, and an outlay of cash for a new set of keys are extra annoyances when this happens.

Did you ever imagine the same thing happening with your pastures? Think about it: if you run livestock on rangeland, what happens when key forage species get overgrazed? Gradually, livestock will selectively graze out the key species, and before you know it, forbs or less desirable species have replaced the good stuff and left you wondering what happened to your "keys."

If you recognize this problem early, it's possible to adjust the stocking rate and/or grazing management to sustain the key species and maintain or gradually increase pasture productivity. Failing to recognize this situation-or recognizing it but not adjusting grazing management - often leads to frustration, finger-pointing at the weather man, and, for the impatient, thoughts of converting native grass to bermudagrass or the latest wonder grass on the market - in effect, making new keys.

Many times with tame pasture, such as bermudagrass, we suggest stocking rates based on the total amount of expected production, combined with the level of utilization that we think corresponds to a producer's grazing management skills and that also will sustain plant vigor. For an experienced producer in the southern Great Plains with a fertilized stand of bermudagrass that will yield an estimated 2.5 tons of forage per growing season, we might suggest a seasonal stocking rate based on grazing $70 \%$ of the grass he grows over a 7 -month period. In this case, the stocking rate would be 1.8 acres per 1,100 -pound cow. We often suggest stocking rates on native grass in the same manner, but if we are not conservative in doing so or if the producer does not monitor his pastures, this method can lead to "losing your keys." So, while we may stock based on utilizing $25 \%$ on native grass, the knowledge of and use of key forage species as a management tool enables us to adjust stocking rates in order to keep desirable forages and avoid reducing the productivity of native grass pastures.

To determine your key forage species, you have to know your major plants and a little about what livestock like to eat. Key forage species are normally perennial plants. They should be well distributed and provide a significant proportion of the plant composition in a pasture. They should also be relatively well preferred by the livestock species you are managing. This is where knowing what livestock like to eat proves valuable. About 15 years ago, Jack Cutshall and I were kicking around on a ranch in central Louisiana when he asked me, "If you had the choice of eating a steak or a hot dog, which would you eat?" It was close to dinner, so I said, "I'd eat my steak first, and then if I was still hungry, I'd eat the hot dog." He asked, "Then why do you think the cattle are hammering the Indiangrass in this pasture?" Before I could reply, he said, "The cattle figure they don't know how long they'll be in this pasture, so they're eating their steak first, too!" His message to me was that cattle have preferences for different plants just like people have preferences for different foods. The cattle preferred the Indiangrass over the rest of the forages in the pasture and therefore ate a higher percentage of it than the other forages.

In this case, Indiangrass was the key species, and if grazing management were not addressed, the abundance of this 

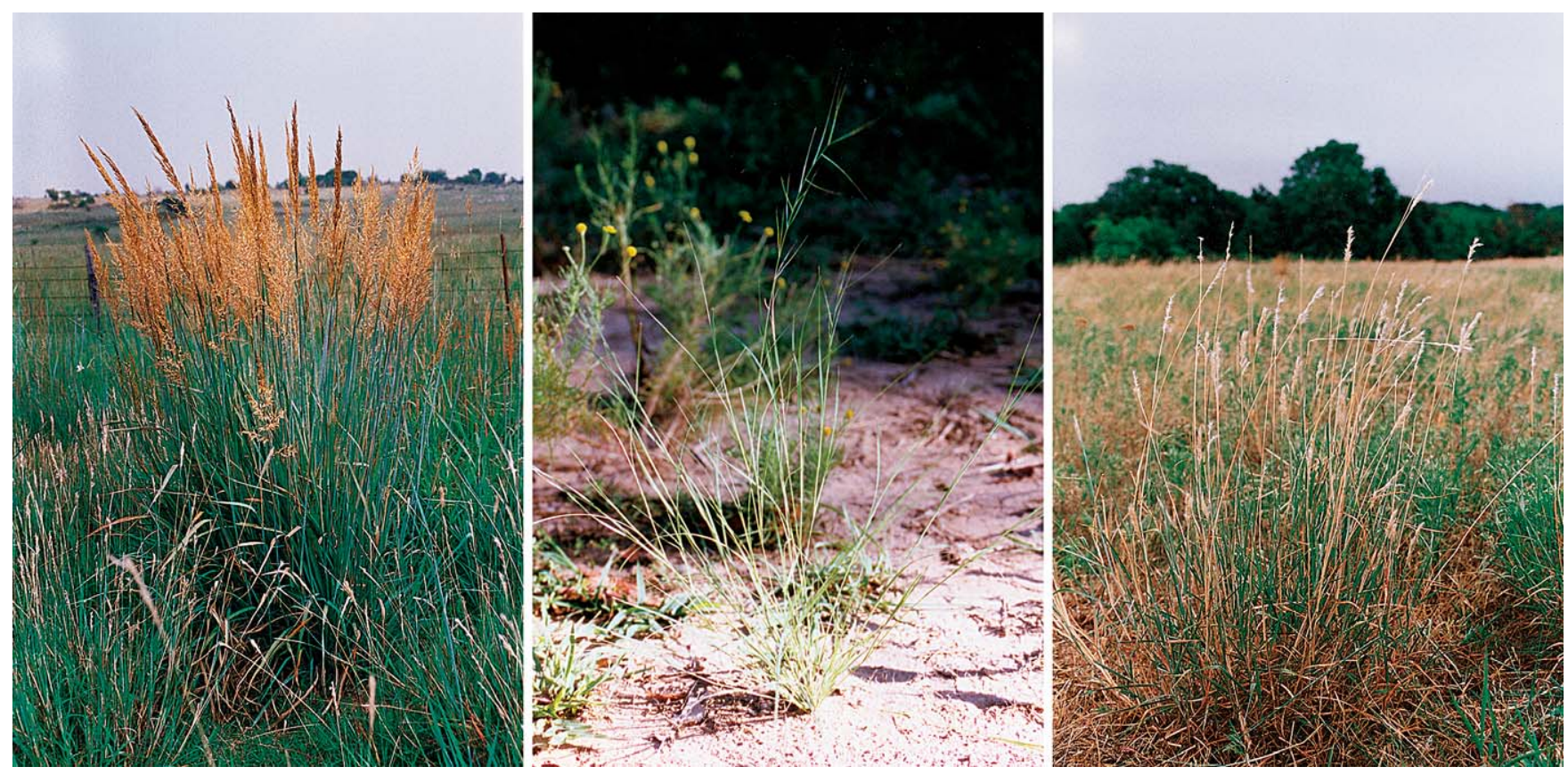

Photo 1. Left to right: Indiangrass, oldfield threeawn, and silver bluestem.

important plant would be reduced, and it would be gradually replaced by less desirable species, which most likely would reduce the carrying capacity of the pasture. The picture depicts 3 native grasses: Indiangrass, oldfield threeawn, and silver bluestem. If you had a pasture containing all these plants, it is highly likely that cattle will apply the "steak/hot dog principle" when grazing these plants. Most often, cattle will prefer Indiangrass over silver bluestem and silver bluestem over oldfield threeawn. There are times, such as early spring, when all these forages are selected, and it's harder to discern grazing preferences. However, as the growing season progresses, you will almost always see the Indiangrass grazed harder than the other 2 grasses by cattle. If Indiangrass were abundant enough and distributed fairly well in this pasture, we would consider it the key species.

Now go back to the discussion on stocking native grass pastures based on a percentage of grass utilization. If we stocked this pasture based on 35\% utilization and had enough information to tell us that this pasture should produce 3,000 pounds over a year's time, the suggested yearlong stocking rate would be about 10 acres per 1,100-pound cow. But if we don't monitor the grazing use of key species, cattle may overgraze the Indiangrass, resulting in underuse of the other grasses. With no attention paid to this matter over several years, the composition of plants in the pasture will likely shift to the point that Indiangrass is no longer abundant enough to be considered a key species. Forbs or less desirable grasses replace Indiangrass, and pasture production is reduced. To alleviate this problem, allow the livestock to graze no more than $50 \%$ of the key species. By not overgrazing the key species, remaining forages are much less likely to be overgrazed, and pasture productivity is easier to sustain. It's easi- er to talk about using no more than $50 \%$ of a particular grass than it is to do it. Obviously, this will take some monitoring, or "looking for your keys." The most practical method of doing this is to locate a key area in every pasture. A key area obviously contains the key species, has a high amount of available forage, and has average topography relative to the whole pasture, and the grazing distribution of livestock is not biased by distance to water (too close or too far). A key area should also not be close to feeders, mineral or salting locations, or the lone grove of shade trees in the pasture.

It's not hard to find a key area in each native grass pasture, but you need to get out of the pickup and walk through the area in order to determine the grazing use of the key species. You will get a different perspective looking down on the grass than you will looking across the grass.

The concept of key species and key areas is not new to the range profession. However, it's hard for me to think of a more proven, producer-friendly, grazing management tool. It is also one of the easiest monitoring methods available. Ranchers spend a lot of time on their land - use it wisely by learning your plants and utilizing this simple method. Also, it's probably not a bad idea to keep another set of keys in the barn.

The author is with the Samuel Roberts Noble Foundation (bttp://www.noble.org), headquartered in Ardmore, Okla., a nonprofit organization conducting agricultural, forage improvement, and plant biology research; providing grants to nonprofit charitable, educational, and health organizations; and assisting farmers and ranchers through educational and consultative agricultural programs. Contact Caroline Booth Lara,cblara@noble.org. 